\title{
LA EXTENSIÓN DE LOS EFECTOS DE LA SENTENCIA DICTADA EN PROCESOS PROMOVIDOS PARA LA DEFENSA DE LOS INTERESES COLECTIVOS Y DIFUSOS DE CONSUMIDORES Y USUARIOS: RÉGIMEN EN LA LEY CHILENA DE PROTECCIÓN DEL CONSUMIDOR*
}

\author{
THE EXTENSION OF THE EFFECTS OF THE JUDGMENT PRONOUNCED IN PROCESSES \\ FOR THE DEFENSE OF THE CONSUMERS COLLECTIVE AND DIFFUSE INTERESTS: \\ ReGulation in the Chilean Consumer Protection LaW
}

Maite AguirReZabal Grünstein**

\begin{abstract}
RESUMEN
El presente trabajo tiene como finalidad realizar un estudio de los efectos que puede producir la sentencia dictada en un proceso colectivo. Se estudia la legislación española, brasileña y chilena, a la luz de las soluciones ofrecidas en la materia por la doctrina.

ABSTRACT

The present work has for object the realising of a study of the effects that the judgment pronounced in a class action may produce. It is studied the Spanish, Brazilian and Chilean legislation, at the light of the solutions offered in this matter by the doctrine.
\end{abstract}

PALABRAS CLAVE

Sentencia, Efectos, Consumidor.

KEY WORDS

Judgment, Effects, Consumer.

\section{Planteamiento del problema}

Comparado con los distintos problemas jurídicos tradicionales, el de la protección jurídica de los intereses supraindividuales, especialmente en lo relativo

\footnotetext{
*El presente artículo se elabora en el marco del Proyecto FONDECYT № 11080052, titulado "Análisis crítico del procedimiento contemplado en la Ley 19.496, para la defensa de los intereses colectivos y difusos de consumidores y usuarios", del que la autora es la investigadora responsable. Trabajo recibido el 14 de octubre de 2009 y aprobado el 17 de marzo de 2010.

** Licenciada en Ciencias Jurídicas y Sociales por la Universidad de Valparaíso, Abogada; Doctora en Derecho por la Universidad de Navarra; Profesora titular de la cátedra de Derecho Procesal de la Universidad de los Andes y de su Programa de Doctorado en Derecho y Secretaria Ejecutiva del Programa de Doctorado en Derecho. Correo electrónico: maguirrezabal@uandes.c.
} 
a la protección de los consumidores y usuarios, tiene una historia relativamente corta ${ }^{1}$. Hasta finales del siglo pasado, la figura del consumidor no tenía importancia en el orden económico y social, puesto que se pensaba que los mecanismos del mercado, dentro de un sistema de equilibrios económicos, eran capaces por sí mismos de asegurar su protección. Esta situación se vio pronto superada como consecuencia del desarrollo y desenvolvimiento económico que generó una tendencia monopolística dentro del mercado. El Estado surge entonces como representación de un poder institucionalizado y encomendado a la protección de la libertad de los sujetos en cuanto a sus relaciones económicas.

Lo anterior se manifiesta principalmente en el fenómeno de la contratación en masa, que uniforma las cláusulas contractuales y establece condiciones generales en la contratación como respuesta a la necesidad de distribuir productos o servicios homogéneos².

Esta etapa se caracteriza también por la politización de los derechos sociales, económicos y culturales, y se desarrollan dos fenómenos que son indisociables: la emergencia de nuevos grupos sociales de particulares condiciones y la identificación y categorización de intereses que si bien se pueden determinar de pertenencia individual, en razón de su importancia colectiva se establecen como propios de esos grupos o categorías sociales y que han sido denominados por la doctrina intereses supraindividuales o transindividuales ${ }^{3}$.

Ellos se enmarcan dentro de lo que se ha conocido como derechos de tercera generación o derechos humanos de la solidaridad, que encuentran su origen científico en la teoría de VASAK, sobre la dimensión internacional de los derechos del hombre. Junto a la reconocida distinción entre derechos civiles,

\footnotetext{
${ }^{1}$ Solamente en los años sesenta se multiplican las declaraciones y normativas tendentes a la protección del consumidor. Estados Unidos fue el pionero en plasmar la defensa de los consumidores, y siguiendo el ejemplo norteamericano los países industrializados han reaccionado de forma paralela. Fue a partir del mensaje al Congreso que diera el día 19 de marzo de 1962 el presidente John F. Kennedy sobre la protección de los intereses de los consumidores con el que se inició el movimiento de protección y defensa de los mismos, y que se extendió con mucha rapidez, creándose asociaciones, doctrina y leyes especiales para esta materia. En Inglaterra destaca la Consumer Protection Act, de 1961.

${ }^{2}$ Cfr. Rodríguez López, Ricardo, "Tutela jurisdiccional de los derechos de los consumidores y usuarios", Actualidad Civil 3, 1993, p. 402. En este mismo sentido Bonet NAVARRO, Ángel, "Protección eficaz y acceso a la justicia de los consumidores", Estudios sobre Consumo 16, 1989, p. 20, quien señala que "aquí opera una paradoja que, considerada en su estructura, puede explicar, bien que parcialmente, los efectos del fenómenos del consumo. Mientras que el producto se acerca al consumidor por una publicidad que se le ofrece rompiendo la frontera de la intimidad privada del ciudadano, el productor responsable del producto se aleja del consumidor, bien físicamente por el establecimiento lejano del centro de producción, bien jurídicamente por la interposición de intermediarios, lo que crea trabas en orden a la exigencia de la calidad y del cumplimiento de lo que impone la buena fe contractual".

${ }^{3}$ Para un estudio en extenso de la noción de interés supraindividual, vid. AguirReZABal Grünstein, Maite, "Algunas precisiones en torno a los intereses supraindividuales (colectivos y difusos)", Revista Chilena de Derecho volumen XXXIII No 1, 2006, pp. 21-39.
} 
políticos, económicos y culturales, habla de estos nuevos derechos, que son aquellos que proceden de una cierta concepción de la vida en comunidad, y sólo se pueden realizar por la conjunción de los esfuerzos de todos los que participan en la vida social ${ }^{4}$.

Es un principio generalmente aceptado por las culturas jurídicas de todos los tiempos que, en consideración de la seguridad jurídica, la sentencia que pone fin a una situación controvertida ha de alcanzar un grado de firmeza que la haga inamovible. En efecto, la sentencia puede verse como algo inmutable o como una resolución revisable, pero incluso en este último caso dicha revisión se debe someter a importantes restricciones, porque de lo contrario la inseguridad jurídica haría sentir sus graves consecuencias.

Por lo tanto, y desde una perspectiva netamente jurídica, las nociones de "sentencia", "seguridad jurídica" y "cosa juzgada", son indisociables.

El concepto mismo de cosa juzgada se ha mantenido invariable durante prácticamente cincuenta años y por lo mismo, no es de extrañar que sigan vigentes las ideas que sobre el particular enuncia Vodanovic en los siguientes términos: "Autoridad de cosa juzgada es el valor normativo que el fallo tiene, en cuanto a la materia decidida, en las relaciones entre las partes y sus causahabientes u otros sujetos y, también, respecto de los jueces. Las partes y otras personas sometidas a la autoridad de la cosa juzgada no pueden hacer valer ninguna pretensión que contradiga la declaración del fallo, y los jueces no pueden acoger tampoco peticiones que estén en pugna con esa declaración"s.

La cosa juzgada tradicional tiene límites objetivos y subjetivos. Los primeros se refieren al thema decidendum, en cuanto a que su fuerza se extiende a las cuestiones litigiosas amparadas por la cosa juzgada, tanto en los fundamentos de la sentencia como en su parte dispositiva. En cuanto a los límites subjetivos rige el principio 'res inter alios iudicata aliis nequeprodesse neque nocere potest', es decir, que afecta solamente a quienes fueron partes en el proceso, y no puede favorecer ni perjudicar ${ }^{6}$.

Es evidente, entonces, que se requiere de un análisis científico que se detenga exhaustivamente en el tema de la cosa juzgada en materia de intereses supraindividuales y las nuevas tendencias que surgen en el Derecho comparado.

\footnotetext{
${ }^{4}$ Cfr. VaSAK Karel, "Human rights: as a legal reality", The international dimensions of human rights, Greenwood Press, Connecticut, 1982, pp. 3-10.

${ }^{5}$ Vodanovic, Antonio, Curso de Derecho Civil, Parte General y Sujetos del Derecho, $4{ }^{a}$ edición, Editorial Nascimento, Santiago de Chile, 1971, pp. 82-83.

${ }^{6}$ Regla que además consagra nuestro Código Civil como solución general, cuando en su artículo $3^{\circ}$ inciso $2^{\circ}$ dispone que "las sentencias judiciales no tienen fuerza obligatoria sino respecto de las causas en que actualmente se pronunciaren". Es decir, los efectos de la sentencia se producen únicamente respecto de las partes que han litigado en el proceso, lo que constituye un mecanismo de defensa de los derechos y garantías procesales de quienes no han sido partes.
} 


\section{LA PRETENDIDA EXTENSIÓN A TERCEROS DE LA}

\section{COSA JUZGADA EN MATERIA DE PROCEDIMIENTOS COLECTIVOS}

Uno de los mayores problemas que suscita la tutela jurisdiccional de los intereses supraindividuales es determinar la extensión de los efectos de la sentencia que resuelva las pretensiones de tutela de los mismos ${ }^{7}$. Ante la ausencia de una norma especial sobre el particular, la doctrina se ha pronunciado en diversos sentidos: desde los que sostenían la eficacia ultra partes de la sentencia, a los que proponían atender a los límites subjetivos normales de eficacia interpartes, o los que propugnaban la producción de cosa juzgada secundum eventum

\footnotetext{
${ }^{7}$ Cfr. Gómez de Liaño González, Fernando, "La legitimación colectiva y el artículo $7^{\circ}$ de la Ley Orgánica del Poder Judicial", Justicia 3, 1986, p. 576, quien considera que la legitimación colectiva derivada de este artículo "origina asimismo una eficacia 'ultra partes de la sentencia' que afecta a quienes no han sido partes en sentido formal, pero son titulares como integrantes del grupo afectado de una misma relación. Y se verán sujetos por la ejecución de la sentencia". En el mismo sentido, Cordón MORENO, Faustino, "El acceso a la justicia civil de los derechos de los consumidores", Estudios sobre consumo 16, 1989, p. 130, quien señala que "no se resentirían las estructuras procesales civiles por el hecho de que la sentencia de condena desplegase una eficacia ultra partes, siempre que, por respeto al principio de libre disposición de los derechos, se dejase a la parte individual la iniciativa en la ejecución...", agregando luego que la doctrina del Tribunal Constitucional sostiene que puede existir indefensión formal sin que necesariamente se produzca una indefensión de carácter material. El fundamento de la eficacia ultrapartes lo encontramos en el principio de economía procesal y en el evitar las decisiones contradictorias, impidiendo así un derroche de actividad jurisdiccional y asegurando la igualdad de tratamiento de los sujetos dependientes de una única situación sustancial objeto de pronunciamiento jurisdiccional. En este mismo sentido, PelleGrinI GrINOver, Ada, "Eficacia y autoridad de la sentencia: el Código Modelo para Iberoamérica y la teoría de Liebman", en La tutela de los derechos difusos, colectivos e individuales homogéneos. Hacia un Código Modelo para Iberoamérica, Ed. Porrúa, México, 2003, p. 256, quien siguiendo a LieBMAN, Enrico Tulio, Eficacia y autoridad de la sentencia, Traducción de Sentís Melendo, Santiago, Ediar, Buenos Aires, 1939, p. 6, distingue entre la eficacia y la autoridad de la sentencia y es con base en esa distinción que "Liebman resuelve el problema de la eficacia de la sentencia con relación a terceros: la limitación subjetiva de la cosa juzgada a las partes y sus sucesores (posteriores a la demanda judicial) es una cosa; pero ella no excluye la extensión subjetiva de la eficacia de la sentencia a terceros", y agrega luego que la sentencia se encuentra firme, es inmutable para las partes, pero no así para los terceros, quienes pueden sublevarse contra esta eficacia natural de la sentencia.
}

${ }^{8}$ Cfr. De la Oliva Santos, Andrés, "Sobre la protección jurisdiccional de los consumidores y usuarios", Estudios sobre consumo 16, 1989, p. 161, quien afirma que en la doctrina "anida una confusión lo suficientemente grande como para que se dude del principio res iudicata inter partes, por el que en virtud del intangible principio de audiencia ("nadie debe ser condenado sin ser oído y vencido en juicio"), los efectos vinculantes de la sentencia que recaen en un proceso entre A y B no pueden afectar a C, por más que la situación jurídica constitutiva de la res in indicio deducta sea común a $\mathrm{A}, \mathrm{B}$ y C". En este mismo sentido, cfr. Bordalí Salamanca, Andrés, "Efectos de la sentencia pronunciada en los procesos de tutela de intereses o derechos difusos", en Procesos colectivos. La tutela de los derechos difusos, colectivos e individuales en una perspectiva comparada, Ed. Porrúa, México, 2003, p. 308, GutiéRREZ de CABIEDES, Pablo, La tutela jurisdiccional de los intereses supraindividuales: colectivos y difusos, Aranzadi, Navarra, pp. 432 y ss. y Punzı, Carlo, "La tutela giudiziale degli interesi diffusi e degli interessi colletivi", Rivista di Diritto Processuale 3, 1948, pp. 275 y ss. 
litis $^{9}$, que ha sido generalmente entendida por la doctrina en el sentido de que si la sentencia es favorable a las pretensiones deducidas ésta debe expandir sus efectos al resto de la colectividad, y si es desfavorable debe sólo producir efectos interpartes, por lo que los legitimados podrían demandar nuevamente basando la demanda en los mismos hechos ${ }^{10}$.

La idea de la extensión de la cosa juzgada a terceros tiene su origen en la obra de Cappelletti" ${ }^{1}$, que plantea que en materia de intereses supraindividuales deben superarse las estructuras tradicionales del proceso basado en el garantismo individualista, para dar paso a nuevas figuras, entre las que se encuentra la extensión de la eficacia de la cosa juzgada a terceros ajenos al proceso ${ }^{12}$.

La doctrina también venía considerando como necesario extender la eficacia de la sentencia respecto de toda la colectividad interesada, aunque algunos de los individuos afectados hubieran estado apartados del proceso en que se dictó la sentencia que se pronuncia sobre el interés supraindividual. Al momento de determinar los efectos de esta sentencia, la doctrina se dividía entre aquellos que propugnaban la eficacia ultra partes de la sentencia favorable o desfavorable respecto de todos aquellos miembros del grupo o colectividad portadora del interés, aunque hubieren permanecido ausentes en el proceso y entre los que exigían el respeto del derecho de defensa de los miembros ausentes ${ }^{13}$.

\footnotetext{
${ }^{9}$ Cfr. Almagro Nosete, José, "La protección procesal de los intereses difusos en España", Justicia № 1, 1983, p. 86, y Acosta Estévez, José, Tutela procesal de los consumidores, Bosch, Barcelona, 1995, p. 137.

${ }^{10}$ Esta solución, como se analizará más adelante en el presente trabajo, ha sido recogida por el Derecho Brasileño en la tutela de intereses supraindividuales. Así, la cosa juzgada producirá efectos erga omnes salvo en el caso en que la demanda sea rechazada por insuficiencia de pruebas, caso en el produce efectos secundum eventum litis. Cfr. en este sentido Pellegrini Grinover, Ada, "El nuevo proceso brasileño del consumidor", Estudios sobre Consumo 25, 1992, pp. 13-24. En sentido contrario, GIDI, Antonio, "Cosa juzgada en acciones colectivas", en La tutela de los derechos difusos, colectivos e individuales homogéneos. Hacia un Código Modelo para Iberoamérica, Ed. Porrúa, México, 2003, pp. 273-274, señala que estos efectos secundum eventum litis se forman precisamente cuando la sentencia es favorable a la pretensión deducida, y no cuando es desfavorable, como suele señalar la doctrina. La sentencia tendrá una extensión de sus efectos de cosa juzgada de acuerdo a esta fórmula cuando la acción colectiva es acogida por el tribunal, de modo tal que dicha sentencia hará cosa juzgada erga omnes o ultra partes para tutelar el bien colectivo, vinculando a la comunidad o al colectivo titular del derecho supraindividual, y vinculando también, positivamente y en su esfera individual, a los titulares de derechos individuales homogéneos que pertenecen a esa comunidad o colectivo. Ese sería el sentido, a juicio de este autor, de la extensión de los efectos de cosa juzgada secundum eventum litis.

${ }^{11}$ Cappellettı, Mauro, "Appunti sulla tutela giurisdizionale di interessi collettivi o diffusi", en Le azioni a tutela di interessi colletivi. Atti del convegno di studio (Pavia, 11-12 giugno 1974), Cedam, Padova, 1976, p. 56.

${ }^{12}$ Cfr. en este sentido, CARPI, Federico, L'efficaccia ultra partes della sentenza civile, Ed. Giuffrè, Milano, 1974 , p. 80.

${ }^{13}$ En este sentido, De LA Oliva Santos, Andrés, Sobre la cosa juzgada (civil, contencioso-administrativa y penal, con examen de la jurisprudencia del Tribunal Constitucional), Centro de Estudios Ramón Areces, Madrid, 1991, pp. 48-49, quien señala que "en términos generales, cabe afirmar que el principio
} 
Esta segunda posición, señalaba que el principio de defensa de los individuos que no han intervenido en el proceso induce a excluirlos de los efectos extintivos de la sentencia denegatoria, pero la sentencia que acoja la demanda valdrá para todos los miembros de la colectividad ${ }^{14}$. De esta forma se atribuye a la sentencia una eficacia "secundum eventum litis"15, esto es, la que acoja la demanda valdrá para todos los miembros, mientras que la que la desestime sólo tendrá eficacia "interpartes".

Por lo tanto, se establece la eficacia de la sentencia dependiendo del resultado de la misma, lo que, a juicio de parte de la doctrina, no parece muy ortodoxo $^{16}$, ya que impondría una carga excesiva para la contraparte al no ser oponible a terceros la sentencia desestimatoria, porque tendría que defenderse en juicio un número ilimitado de veces, siempre por lo mismo y sin poder oponer nunca la eficacia de la sentencia en los procesos que se inicien ${ }^{17}$. A lo anterior,

de audiencia (o de contradicción, según otros gustan denominarlo) ha de impedir que la sentencia que pone fin a un proceso afecte negativamente a quienes no han sido partes en ese proceso, pero, no, insistimos, que les afecte negativamente de cualquier forma, sino por incidir sobre una situación jurídica de esos terceros procesales que sea idéntica a la de las partes o sobre derechos -no simples intereses, de cualquier intensidad- propios de esos terceros, también idénticos a los de los litigantes, o, cuando menos, en situaciones o derechos directamente ligados a aquéllos, de las partes procesales, sobre los que sí versó pronunciamiento jurisdiccional"; y Bellido Penadés, Rafael, La tutela frente a la competencia desleal en el proceso civil, Ed. Comares, Granada, 1998, pp. 228-232.

${ }^{14}$ Defendida por ejemplo por Proto PISANI, Andrea, "Appunti preliminari per uno studio sulla tutela giurisdizionale degli interessi collettivi (o piu esattamente supraindividuali) innanzi al giudice civile ordinario", en Le azioni a tutela di interessi collettivi, Ed. Cedam, Padova, 1976, p. 285, DeNTI, Vittorio, "Le azioni a tutela di interessi collettivi", en Le azioni a tutela di interessi collettivi, Ed. Cedam, Padova, 1976, pp. 3-22, y Barbosa Moreira, José, "A açao popular do direito brasileiro", en Studi in onore di Enrico Tullio Liebman, volumen IV, Ed. Guiffrè, Milano, 1979, p. 2690, en donde se argumenta que la solución al problema de la cosa juzgada en acciones colectivas deriva de la instauración de una distinción entre las hipótesis de procedencia e improcedencia de la acción colectiva. Así, la sentencia que acoja la demanda tendrá una eficacia erga omnes, y la que deniegue la demanda sólo tendrá un efecto "inter partes".

${ }^{15}$ Los juristas del derecho civil denominan a esta situación una extensión in utilibus (del latín "útil") de la sentencia colectiva, porque solamente se extiende la decisión si es favorable a los intereses del grupo. También se le denomina secundum eventum litis, porque depende del resultado del litigio.

${ }^{16}$ Cfr. en este sentido, VIGORITI, Vincenzo, Interessi Collettivi e proceso, La legitimazione ad gire, Ed. Giuffrè, Milano, 1979, pp. 110-112, quien señala que esta solución constituye una desviación de los principios generales y que, por lo tanto, debe considerarse con mucha cautela.

${ }^{17} \mathrm{Cfr}$. TAPIA Fernández, Isabel, "Artículo 221. Sentencias dictadas en procesos promovidos por asociaciones de consumidores y usuarios", en Comentarios a la Ley de Enjuiciamiento Civil, Ed. Aranzadi, Navarra, 2000, pp. 807-808. En este mismo sentido, Garnica Martín, Juan, "Artículo 221. Sentencias dictadas en procesos promovidos por asociaciones de consumidores y usuarios", en Comentarios a la nueva Ley de Enjuiciamiento Civil, Ed. Iurgium, Barcelona, 2000, p. 857, considera que la extensión ultra partes de los efectos del proceso es censurable y a la que se puede reprochar a la vista del principio de audiencia y del artículo 24.1 de la Constitución Política española, pero cree que era la opción más razonable porque es la que menos cuestiones suscita y también la más justa desde la perspectiva del demandado. El legislador opta por un sistema cerrado en el que el ejercicio de la acción del grupo cierra el paso a cualquiera otra acción posterior, tanto individual como de grupo. 
se agrega que la posibilidad de extender los efectos "secundum eventum litis" ha sido rechazada por la doctrina que promueve la existencia de un "ideological plaintiff", es decir, un representante adecuado que lucha de forma correcta y tenaz por los intereses del grupo ${ }^{18}$.

\section{Referencias de Derecho Comparado}

\section{Régimen en la Ley de Enjuiciamiento Civil Española}

La nueva Ley de Enjuiciamiento Civil de 2000 (en adelante LEC), contiene dos normas importantes en relación con la extensión de los efectos de la sentencia y de la cosa juzgada: el artículo 221, en el que establece una regulación especial sobre el contenido y los efectos de la sentencia dictada en un proceso iniciado como consecuencia de una demanda interpuesta por una asociación de consumidores y usuarios, con base en la legitimación que se les reconoce en el artículo 11 LEC, y el artículo 222.3 LEC, que dispone que "la cosa juzgada afectará a las partes del proceso en que se dicte..., así como a los sujetos no litigantes, titulares de los derechos que fundamenten la legitimación de las partes conforme a lo previsto en el artículo 11 de esta Ley"19.

Se aparta el legislador español de las soluciones aportadas por otras legislaciones comparadas, atribuyéndole a la sentencia eficacia preclusiva también respecto de las pretensiones individuales, sea ésta favorable o desfavorable, consagrando el efecto erga omnes de la sentencia dictada en un procedimiento colectivo como uno de sus requisitos esenciales ${ }^{20}$.

Esta eficacia erga omnes llevada hasta las últimas consecuencias ha sido criticada por un sector de la doctrina, especialmente en lo que respecta a la garantía del derecho de defensa de los miembros ausentes, especialmente si se trata de grupos indeterminados o de difícil determinación, en que sus miem-

\footnotetext{
${ }^{18}$ Cfr. en este sentido, Cappellettı, "Appunti sulla tutela", cit. nota n. 11, p. 192, quien no considera válida esta opción si se tiene en cuenta la flexibilidad del concepto de adecuada representatividad, ya que si la parte es un adecuado representante de los miembros del grupo, no debe distinguirse entre efectos favorables y desfavorables puesto que debe entenderse que los ausentes han sido adecuadamente representados. De ahí que las distintas legislaciones se preocupen de controlar de modo preferente esta representación adecuada de los miembros del grupo.

${ }^{19}$ El artículo 11 de la Ley de Enjuiciamiento Civil española otorga legitimación para la defensa de intereses supraindividuales a cualquier perjudicado de modo individual, a las asociaciones de consumidores y usuarios, a las entidades legalmente constituidas para defender en juicio los derechos e intereses de sus asociados y los de la asociación, así como los intereses generales de los consumidores y usuarios; también a los grupos de afectados, cuando se trate de intereses colectivos y exclusivamente a las asociaciones de consumidores y usuarios, si te trata de intereses difusos.

${ }^{20}$ Con esta solución se aparta el legislador español de la solución que la jurisprudencia del Tribunal Supremo había establecido respecto de la legitimación del comunero en la comunidad de bienes, en que sólo se acoge la extensión de los efectos de la sentencia al resto de los comuneros cuando ésta sea favorable. Cfr. en este sentido, Sentencia del Tribunal Supremo 1984/84, de 6 de febrero de 1984.
} 
bros no hubiesen tomado conocimiento de la existencia de la demanda o de la sentencia de la que podrían beneficiarse ${ }^{21}$.

Los efectos de la sentencia que no hayan intervenido cuando nos encontramos ante supuestos en que su contenido afecte. A las sentencias dictadas en estas circunstancias y que afectan a una pluralidad indeterminada de perjudicados se les conoce con el nombre de condenas abiertas, y el artículo 222 LEC, lejos de configurar un supuesto especial de extensión de cosa juzgada a terceros, lo que hace es regular las consecuencias que esta situación produce en relación con una categoría especial de sujetos propia de estos procesos, las partes ausentes, tal como las ha denominado la doctrina ${ }^{22}$.

A su vez, el artículo 221 de la LEC regula el objeto del proceso desde el punto de vista de la sentencia y, conjuntamente con el artículo 11 -relativo a la legitimación-, establece reglas especiales sobre la eficacia subjetiva de la sentencia en procesos que afecten a consumidores y usuarios ${ }^{23}$.

${ }^{21}$ En este sentido, señala Silguero Estagnan, Joaquín, "Las acciones colectivas de grupo en España", en Procesos Colectivos, La tutela de los derechos difusos, colectivos e individuales homogéneos en una perspectiva comparada, Ed. Porrúa, México, 2004, p. 361, que "para todos estos casos, sería más correcto reducir a sus justos términos la indeterminación de los miembros del grupo. En efecto, la indeterminación o la difícil determinación de los miembros del grupo, justifica que se atribuya legitimación a las asociaciones de consumidores y usuarios (art. 11.3 LEC), pero no tiene por qué derivar en una exclusión de la legitimación propia que al consumidor o usuario afectado le pueda corresponder y que, el mismo art. 11 LEC deja subsistente de forma expresa". Y aunque el artículo 15 LEC, a propósito de la publicidad e intervención en procesos para la protección de derechos e intereses colectivos y difusos de consumidores y usuarios, contempla un régimen especial para los grupos de miembros indeterminados o de difícil determinación que cierra o excluye cualquier posibilidad de intervención procesal.

${ }^{22}$ Cfr. en este sentido CAPpellettı, Mauro, "Formaciones sociales e intereses de grupo frente a la justicia civil", Traducción de Brañes, Raúl, Boletín Mexicano de Derecho Comparado 31-32 Año XI, eneroagosto, 1978, pp. 33 y ss.

${ }^{23}$ Dispone este artículo que "Sin perjuicio de lo dispuesto en los artículos anteriores, las sentencias dictadas a consecuencia de demandas interpuestas por asociaciones de consumidores o usuarios con la legitimación a que se refiere el artículo 11 de esta ley estarán sujetas a las siguientes reglas:

1) Si se hubiere pretendido una condena dineraria, de hacer, no hacer o dar cosa específica o genérica, la sentencia estimatoria determinará individualmente los consumidores y usuarios que, conforme a las leyes sobre su protección, han de entenderse beneficiados por la condena. Cuando la determinación individual no sea posible, la sentencia establecerá los datos, características y requisitos necesarios para poder exigir el pago y, en su caso, instar la ejecución o intervenir en ella, si la instara la asociación demandante.

2) $\mathrm{Si}$, como presupuesto de la condena o como pronunciamiento principal o único, se declarara ilícita o no conforme a la ley una determinada actividad o conducta, la sentencia determinará si, conforme a la legislación de protección a los consumidores y usuarios, la declaración ha de surtir efectos procesales no limitados a quienes hayan sido partes en el proceso correspondiente.

3) Si se hubieren personado consumidores o usuarios determinados, la sentencia habrá de pronunciarse expresamente sobre sus pretensiones.

En las sentencias estimatorias de una acción de cesación en defensa de los intereses colectivos y de los intereses difusos de los consumidores y usuarios el Tribunal, si lo estima procedente, y con cargo al demandado, podrá acordar la publicación total o parcial de la sentencia o, cuando los efectos de la infracción puedan mantenerse a lo largo del tiempo, una declaración rectificadora". 
Dispone que, según cual sea el objeto litigioso, es decir, la concreta tutela que se solicite, sea el propio juez el que indique en su sentencia qué eficacia tiene respecto de los sujetos jurídicos que directa o indirectamente se pudieran ver afectados por la misma. La Exposición de Motivos así lo entiende cuando expresa que "la diversidad de casos de protección impone evitar una errónea norma generalizadora. Se dispone, en consecuencia, que el Tribunal indicará la eficacia que corresponda a la sentencia según su contenido y conforme a la tutela otorgada por la vigente ley sustantiva protectora de los derechos e intereses en juego".

Ni el artículo 221 ni el artículo 519 LEC ${ }^{24}$, relativo a la acción ejecutiva en el proceso de consumidores y usuarios, hacen referencia a los grupos de afectados, omisión que no parece tener justificación y que deberá ser suplida con una interpretación amplia del precepto. Esta exclusión podría deberse a que el trámite parlamentario en esta materia resultó accidentado, ya que en principio, el artículo 11 LEC no contemplaba la legitimación de los grupos de afectados, pero luego dicho artículo fue modificado en ese sentido y se omitió la consecuente modificación de los artículos 221 y 519 LEC ${ }^{25}$.

Concordamos con Bellido en el sentido que, en definitiva, la norma resultará aplicable siempre que el proceso se inicie por entes con legitimación conforme a los apartados segundo y tercero del artículo 11 LEC, y siempre que se hayan practicado las diligencias de publicidad e intervención previstas en el artículo

\footnotetext{
${ }^{24}$ Este artículo, relativo a acción ejecutiva de consumidores y usuarios fundada en sentencia de condena sin determinación individual de los beneficiados, dispone que "Cuando las sentencias de condena a que se refiere la regla primera del artículo 221 no hubiesen determinado los consumidores o usuarios individuales beneficiados por aquélla, el tribunal competente para la ejecución, a solicitud de uno o varios interesados y con audiencia del condenado, dictará auto en que resolverá si, según los datos, características y requisitos establecidos en la sentencia, reconoce a los solicitantes como beneficiarios de la condena. Con testimonio de este auto, los sujetos reconocidos podrán instar la ejecución".
}

${ }^{25}$ Cfr. Garnica Martín, Juan, "Art. 221", cit. nota n. 17, pp. 857-858. En este mismo sentido Bellido Penadés, Rafael, "La tutela de los intereses de los consumidores en la nueva Ley de Enjuiciamiento Civil", Tribunales de Justicia 1139, 2002, p. 15, quien agrega que la norma debiera entenderse igualmente aplicable a las sentencias dictadas en procesos iniciados por entidades legalmente constituidas o por grupos de afectados y que el 222.3 LEC no exige para que los efectos de la cosa juzgada se extiendan ultra partes que el proceso haya sido iniciado por una asociación de consumidores y usuarios. Opina BACHMAIER WINTER, Lorena, "Cuestiones procesales relativas a la defensa de los intereses colectivos de los consumidores y usuarios por el grupo de afectados", en Derecho de consumo, Acceso a la justicia, responsabilidad y garantía, Ministerio de Sanidad y Consumo, Consejo General del Poder Judicial, Madrid, 2001, pp. 246-247, que no alcanza a comprenderse por qué cuando la tutela la ejercita una asociación de consumidores y usuarios en el caso de pluralidades determinadas se especifica cuál debe ser el contenido de esa sentencia, y cuando la acción la ejerce el grupo no son exigibles los mismos pronunciamientos, porque la sentencia que ponga fin a un proceso iniciado por un grupo también deberá determinar individualmente a los consumidores beneficiados por la misma. Por lo tanto la necesidad de determinar individualmente los consumidores y usuarios a los que afectará la sentencia existe en todos los supuestos en los que se ejercite una acción de grupo con independencia de quien la ejercite. 
15 LEC, porque éstos son los mecanismos que el legislador ha previsto para extender luego los efectos de la cosa juzgada a titulares no litigantes del derecho o interés controvertido ${ }^{26}$.

\section{Régimen en el Código Brasileño de Defensa del Consumidor}

En el Código Brasileño de Defensa del Consumidor, y en lo que respecta a los derechos supraindividuales (colectivos y difusos), el régimen es el de la eficacia erga omnes de la sentencia, lo que resulta razonable si pensamos que se trata de derechos indivisibles con un tratamiento uniforme para todos los afectados, siendo por tanto la decisión favorable o desfavorable para todos ellos.

En cuanto al régimen de la cosa juzgada en relación con los llamados derechos individuales homogéneos ${ }^{27}$, la legislación brasileña ha optado por adoptar la distinción de Liebman entre cosa juzgada, inmutable para las partes, y eficacia natural de la sentencia, a la cual los terceros pueden oponerse. Según esta teoría, la cosa juzgada no es un efecto de la sentencia y mucho menos puede ser identificada con la eficacia de la misma, sino que la cosa juzgada se agrega a la sentencia para la estabilidad de sus efectos ${ }^{28}$.

${ }^{26}$ Cfr. Bellido, La tutela, cit. nota n. 13, p. 15. Para Damián Moreno, Juan, "Artículo 221", Comentarios a la nueva Ley de Enjuiciamiento Civil, Lex Nova, Valencia, 2000, p. 1439, aunque de la lectura del artículo 221 parece desprenderse que estas especialidades se refieren únicamente al caso en que la acción haya sido entablada por las asociaciones de consumidores o usuarios, parece que estas reglas habría que extenderlas igualmente a los procesos iniciados por el resto de las entidades y grupos que al amparo de lo dispuesto en el artículo 11 tengan conferida legitimación para el ejercicio de este tipo de acciones. Agrega BACHMAIER, "Cuestiones procesales", cit. nota n. 25, pp. 248 y ss., que el problema surge en relación con los procesos promovidos por grupos de afectados, porque será más difícil determinar qué debe entenderse por "sujeto no litigante", expresión utilizada por el artículo 222.3 LEC, puesto que en principio el sujeto litigante es el grupo, integrado por la totalidad de los afectados y no solamente por la mayoría. Tampoco parece ser que se refiera a aquel que opta expresamente por excluirse del grupo, porque como ya señalamos la LEC no ha contemplado la posibilidad del opting out, por lo que debe entenderse que en relación con las acciones colectivas los efectos de la cosa juzgada debe entenderse proyectada sobre todos los sujetos que integran el grupo aunque no hayan comparecido a título personal. y GutiérRez de Cabiedes, Pablo, "La nueva Ley de Enjuiciamiento Civil y los daños con múltiples afectados", en Derecho del consumo. Acceso a la justicia, responsabilidad y garantía. Ministerio de Sanidad y Consumo, Consejo General del Poder Judicial, Madrid, 2001, pp. 196 y ss., considera que esta regla tercera del artículo 222 LEC resulta criticable por su falta de precisión y porque entraña serios riesgos para el principio de audiencia de los justiciables y la libre disposición de sus derechos. En su opinión en el caso de intereses supraindividuales no es necesario alterar el régimen ordinario de eficacia de la sentencia ni los límites subjetivos de la cosa juzgada, porque el acogimiento de la demanda interpuesta por uno de los interesados favorece al resto de los afectados por el mismo hecho.

${ }^{27}$ Que son aquellos derechos subjetivos clásicos, perfectamente individuales y pertenecientes a titulares determinados, a los que la ley les otorga un tratamiento colectivo y en un único proceso, por tener un origen común. Se trata de derechos accidentalmente colectivos, individuales y divisibles, a los que el sistema permite un tratamiento procesal conjunto.

${ }^{28}$ LieBMAN, Eficacia, cit. nota n. 7, p.14. Como ya se señaló, en base a esta distinción el autor resuelve el problema de la eficacia de la sentencia con relación a terceros: la limitación subjetiva de la cosa 
El artículo 103 del Código del Consumidor de Brasil se refiere al efecto de cosa juzgada en las acciones colectivas ${ }^{29}$. La ley brasileña prescribe que una sentencia colectiva obligará a todos los miembros del grupo, pero dicha sentencia no afectará sus derechos individuales ${ }^{30}$. Si la acción colectiva es decidida en favor del grupo, todos los miembros ausentes se benefician de la cosa juzgada. $\mathrm{Si}$ es decidida contra el grupo, ya no podrá volver a ejercerse la pretensión de modo colectivo, pero los miembros del grupo podrán ejercer acciones de carácter individual en defensa de sus derechos individuales.

Por lo tanto, los derechos individuales que existen en la misma controversia no se extinguen, y los miembros del grupo tienen la oportunidad de demandar individualmente para reivindicar esos derechos.

Un ejemplo aclarará esta distinción: el objeto de la acción colectiva ejercitada para prohibir una publicidad engañosa es impedir la difusión del mismo. Si la acción colectiva tiene éxito, no sólo el anuncio será prohibido, sino que todos los miembros del grupo serán beneficiados debido a los efectos obligatorios de la sentencia, lo que obedece a la naturaleza indivisible propia del derecho o interés que se protege. En las acciones individuales por daños, los miembros del grupo no necesitarán probar que el anuncio fue erróneo, sino solamente tendrán que demostrar la relación de causalidad individual y el monto de los daños.

juzgada a las partes y a sus sucesores no excluye la extensión subjetiva de la eficacia de la sentencia a terceros.

${ }^{29}$ Artículo 103 del Código del Consumidor brasileño, que dispone que "En las acciones colectivas de que trata este Código, la sentencia hará cosa juzgada: I. Erga omnes, excepto si el pedido es juzgado improcedente por insuficiencia de pruebas, hipótesis en la cual cualquier legitimado podrá intentar otra acción, con idéntico fundamento, valiéndose de nueva prueba, en la hipótesis del inciso I, párrafo único del artículo 81; II. Ultra partes, pero limitado al grupo, categoría o clase, salvo improcedencia por insuficiencia de pruebas, en los términos del inciso anterior, cuando se trate de la hipótesis prevista en el inciso II del párrafo único del artículo 81; III. Erga omnes, solamente en caso de procedencia del pedido para beneficiar todas las víctimas y sus sucesores, en la hipótesis del inciso III del párrafo único del artículo 81.

Párrafo 1.- Los efectos de la cosa juzgada no perjudicarán los intereses y derechos individuales de los integrantes de la colectividad, del grupo, categoría o clase.

Párrafo 2.- En la hipótesis prevista en el inciso III, en caso de improcedencia del pedido, los interesados que no hubieren intervenido en el proceso como litis consortes podrán proponer acción de indemnización en carácter individual.

Párrafo 3.- Los efectos de la cosa juzgada de que cuida el artículo 16, en combinación con el artículo 13 de la Ley № 7.347 de 24 de julio de 1985, no perjudicarán las acciones de indemnización por daños personalmente sufridos propuestas individualmente o en la forma prevista en este Código, pero, si es procedente el pedido, beneficiarán a las víctimas y a sus sucesores, que podrán proceder a la liquidación y a la ejecución en los términos de los artículos 96 a 99.

Párrafo 4.- Se aplica lo dispuesto en el párrafo anterior a la sentencia penal condenatoria".

${ }^{30}$ En el derecho norteamericano, un efecto similar de la cosa juzgada puede encontrarse en juicios de accionistas en representación de una empresa (shareholder derivative suits) y en juicios de accionistas contra deliberaciones de los dirigentes de la compañía (shareholders suits against company board deliberations). 
Si la acción colectiva fracasa, el anuncio no será considerado engañoso y no será prohibido. Esta sentencia es cosa juzgada, y el grupo ya no tiene una segunda oportunidad. Aunque el grupo ya no tiene derecho a proponer otra acción colectiva para obtener la prohibición bajo la misma causa de pedir, los miembros del grupo todavía podrán ejercer acciones individuales por los daños que pudieran derivar de esa publicidad engañosa. Debido a que en la acción colectiva las personas interesadas no son necesariamente partes del juicio, o Ilamadas a comparecer en el tribunal o estar informadas de la existencia de la acción, el legislador brasileño consideró aceptable que una persona se beneficiara de la sentencia colectiva, pero no que fuera perjudicada por ella ${ }^{31}$. En consecuencia, de acuerdo con las leyes brasileñas de las acciones colectivas, solamente los beneficios de la sentencia colectiva se extienden a los miembros individuales ausentes y estos mismos miembros no pueden ser perjudicados por una sentencia desfavorable ${ }^{32}$.

Es necesario explicar también los efectos de la sentencia cuando la acción colectiva tiene por objeto proteger derechos individuales homogéneos, en que lo que se persigue es declarar la responsabilidad del demandado. En caso de que tenga éxito la acción colectiva, cada miembro del grupo debe presentar su propio caso ante el tribunal para establecer que es un miembro del grupo y probar el monto y la extensión de los daños individuales sufridos ${ }^{33}$. Si la acción colectiva se decide contra el grupo, sus miembros no son perjudicados por la sentencia colectiva y pueden promover sus propias acciones individuales en protección de sus derechos individuales. Si el miembro del grupo intervino en la acción colectiva, sin embargo, estará obligado por la sentencia desfavorable ${ }^{34}$.

\section{Régimen en el Código Modelo de Procesos Colectivos para Iberoamérica}

Tomando estas ideas propuestas por la legislación brasileña, en el Código Modelo de Procesos Colectivos para Iberoamérica, se establece que, tratándose de los derechos esencialmente supraindividuales (colectivos y difusos), el régimen de la cosa juzgada implica eficacia erga omnes, en la medida que por la naturaleza indivisible del bien jurídico el resultado de lo juzgado debe ser

\footnotetext{
${ }^{31}$ Ha sido desde hace largo tiempo aceptado en los Estados Unidos que la representación adecuada de intereses de ausentes (así como la notificación adecuada) son requisitos suficientes para encontrarnos frente a un debido proceso legal.

${ }^{32}$ Artículo 103 del Código del Consumidor brasileño. El ejemplo reseñado corresponde a los efectos de una sentencia dictada con ocasión de la tutela de un interés o derecho difuso. La misma regla rige en el caso de los intereses colectivos.

${ }^{33} \mathrm{Y}$ que en definitiva, es el mismo sistema adoptado por la legislación chilena.

${ }^{34}$ Artículo 103 del Código del Consumidor brasileño.
} 
uniforme para todos. Si es favorable lo será para todos, si es contraria, entonces, será desfavorable para todos, salvo en el caso específico en que la pretensión haya sido rechazada por insuficiencia de pruebas ${ }^{35}$, ya que en este caso específico, se ha entendido que no se ha juzgado sobre esos hechos y, por lo tanto, la sentencia no podrá producir este efecto de cosa juzgada ${ }^{36}$.

Así, el artículo 33 del Código Modelo dispone que "En los procesos colectivos de que trata este Código, la sentencia hará cosa juzgada erga omnes, excepto cuando la pretensión fuere rechazada por insuficiencia de pruebas ${ }^{37}$, caso en el cual cualquier legitimado podrá intentar otra acción, con idéntico fundamento, si se valiere de nueva prueba.

Parte $1^{\circ}$. Asimismo, en la hipótesis de rechazo basado en las pruebas producidas, cualquier legitimado podrá intentar otra acción, con idéntico fundamento, en el plazo de 2 (dos) años contados desde el conocimiento de nueva prueba superveniente, que no hubiera podido ser producida en el proceso, siempre que ella sea idónea, por sí sola, para modificar el resultado del proceso.

Parte $2^{\circ}$. Tratándose de intereses o derechos individuales homogéneos, en caso de rechazo de la pretensión, los interesados podrán deducir la acción de indemnización a título individual.

Parte $3^{\circ}$. Los efectos de la cosa juzgada en los procesos de tutela de intereses o derechos difusos, no perjudicarán las acciones de indemnización por daños personalmente sufridos, propuestas individualmente o en la forma prevista en este Código, pero si hubiera sido declarado procedente el pedido, tales efectos beneficiarán a las víctimas y a sus sucesores quienes podrán solicitar la liquidación y la ejecución en los términos de los artículos 22 a 24.

\footnotetext{
35 Pellegrinl, "Eficacia y autoridad", cit. nota n. 10, p. 257, "Por esa razón, el régimen de la cosa juzgada sólo podrá ser de lo juzgado (y de su inmutabilidad) erga omnes, con el único carácter de la sentencia desfavorable por insuficiencia de pruebas, que simplemente no hace cosa juzgada". Cfr. también, Cortés Domínguez, Valentín, Derecho procesal civil. Parte general, $3^{a}$ Edición, Ed. Colex, Madrid, 2000, p. 365.

${ }^{36}$ Esta solución apunta a que para parte de la doctrina, la cosa juzgada no debe verse como algo esencialmente inmutable, ya lo dijo en su época Couture, Eduardo, Fundamentos de Derecho Procesal Civil, Ed. Depalma, Buenos Aires, p. 405, la existencia de la cosa juzgada obedece más a razones políticas que a jurídicas, no es de razón natural si no de exigencia práctica. De la misma opinión fue Chiovenda, Giuseppe, Principios de derecho procesal Civil, vol. II, $5^{\text {a }}$ Edición, Ed. Temis, Buenos Aires, 1965, p. 513.

${ }^{37}$ Montero Aroca, Juan, La prueba en el proceso civil, 4 $4^{a}$ Edición, Ed. Thompson-Civitas, Navarra, 2005, p. 211, hace un distinción entre hecho nuevo y de hecho de nuevo conocimiento, así "cuando se trata de hechos nuevos se está ante una causa objetiva consistente en la nueva ocurrencia de un hecho, pero cuando se trata de hechos de nuevo conocimiento la excepción a la preclusión de la alegación y prueba del hecho es subjetiva -el desconocimiento-.". En todo caso, la sentencia que niega lugar a la pretensión por insuficiencia de pruebas requiere como condición que el juez sentenciador en su decisión indique que el rechazo de la pretensión es debido a esta "insuficiencia de prueba".
} 
Parte $4^{\circ}$. Lo dispuesto en el parágrafo anterior, es aplicable a la sentencia penal condenatoria.

Parte $5^{\circ}$. La competencia territorial del órgano juzgador no implicará una limitación para la cosa juzgada erga omnes.

Combinando las distintas partes del texto legal citado, puede concluirse que la cosa juzgada abarca en el plano colectivo al titular de la acción, portador a su vez de los intereses individuales, impidiendo el ejercicio de nuevas acciones colectivas. Pero, en el plano de los individuos miembros del grupo, la cosa juzgada sólo se hace extensiva para beneficiarlos pero no para perjudicarlos, ya que si la sentencia a sido desfavorable a las pretensiones del colectivo, siempre les quedará a salvo la posibilidad de ejercer acciones individuales.

Además, y para determinar la eficacia y extensión de la cosa juzgada, el Código Modelo distingue entre los intereses supraindividuales propiamente tales y los intereses individuales homogéneos.

El Código además incluye una novedad tratándose de las acciones colectivas pasivas (defendant class action), en que la acción no es propuesta por la colectividad, sino contra una colectividad de personas, siempre que se trate de una entidad organizada ${ }^{38}$ o tenga un representante adecuado y que se trate de un interés colectivo o difuso y no de un interés individual homogéneo.

Así, tratándose de la tutela de derechos indivisibles, el artículo 36 del Código dispone que cuando se trate de intereses o derechos difusos, la cosa juzgada tendrá eficacia erga omnes y vinculará a los miembros del grupo, categoría o clase", lo que significa que los efectos de la cosa juzgada se aplican a todos los miembros del grupo sin excepción alguna. Es una solución lógica si se piensa que estamos ante bienes de naturaleza indivisible y que es esta característica el fundamento de la regla.

Tratándose de intereses individuales homogéneos, el artículo 37 dispone que "cuando se trate de intereses o derechos individuales homogéneos, la cosa juzgada tendrá eficacia erga omnes en el plano colectivo, pero la sentencia que acoja la demanda, no vinculará a los miembros del grupo, categoría o clase, que podrán plantear pretensiones o defensas propias en el proceso de ejecución para dejar sin efecto la eficacia de la decisión en su esfera jurídica individual". Lo anterior significa que el legislador, tratándose de bienes de naturaleza divisible, vuelve a la solución propuesta en el artículo 33 parte $2^{\circ}$, otorgando a los individuos vencidos en la acción colectiva puedan iniciar acciones individuales, por lo que habrá cosa juzgada respecto del grupo, pero no la habrá respecto de cada uno de sus miembros, quienes se encuentran legitimados para iniciar acciones individuales.

${ }^{38}$ Como por ejemplo un sindicato. 


\section{La SOluCión EN LA Ley CHILENA SOBRe \\ Protección de los Consumidores y Usuarios}

Siete años después de su promulgación, la Ley 19.496, sobre la Protección de los Derechos de los Consumidores (en adelante LPC), sufre a través de la modificación introducida por la Ley $N^{\circ}$ 19.955, importantes cambios. Estos cambios obedecen a una evolución en la educación del consumidor en sus derechos y a una toma de conciencia de esos mismos derechos, lo que ha venido acompañado de un rol activo del Servicio Nacional del Consumidor, un incremento importante del número de asociaciones de consumidores constituidas en Chile y de un mayor acceso al crédito. Contribuye también a dicho desarrollo la difusión a través de los medios de comunicación de procesos en que se han visto beneficiados los consumidores y la mayor integración y participación de la ciudadanía en las distintas actividades de la vida comunitaria. Es en este marco en el que se inserta la reforma del año 2004, que posibilita la defensa colectiva de los derechos de los consumidores, y que refuerza la protección ya consagrada en el año 1997.

Se ha entendido por el legislador que una política adecuada de protección, lejos de ser un elemento de distorsión del mercado, es un instrumento necesario para su libertad, ya que tiene por objeto recuperar el equilibrio perdido devolviendo al consumidor su capacidad de elegir libremente. Y lo anterior constituye una paradoja, en el sentido de que para asegurar la libertad del mercado se hace necesaria la intervención normativa y las soluciones judiciales equilibradoras. De ahí que sea necesaria la incorporación de estructuras políticas y normativas que constituyen manifestaciones de la evolución del Derecho en las sociedades jurídicas contemporáneas.

Es en este panorama en el que se enmarca la incorporación de los procedimientos colectivos de consumidores y usuarios ${ }^{39}$, y debe tenerse en cuenta que la reforma sufrida por la Ley de Protección del Consumidor en virtud de la Ley $N^{\circ} 19.955$ es muy reciente y aún no ha generado estudios profundizados y de peso en esta materia, por lo que un estudio dogmático de los intereses que la legislación nacional actualmente protege resulta del todo pertinente y muy conveniente ${ }^{40}$.

\footnotetext{
${ }^{39}$ Sobre el procedimiento para la defensa colectiva de consumidores y usuarios, vid. AguiRREZABAL GRÜNSTEIN, Maite, "El procedimiento para la defensa de intereses colectivos y difusos de consumidores y usuarios en la Ley de Protección del Consumidor", en La protección de los derechos de los consumidores en Chile, Cuaderno de Extensión Jurídica, Facultad de Derecho, Universidad de los Andes, Santiago, 2006, pp. 143-173.

${ }^{40}$ En el Mensaje del Ejecutivo, $\mathrm{N}^{\circ} \mathrm{s}$. 178-344, a propósito de la protección de intereses colectivos y difusos, se señala que el procedimiento se incorpora como "institución que simplificará significativamente la solución de problemas que afectan intereses supraindividuales", agregando luego que "Tal protección viene a dar respuesta a la necesidad de articular herramientas procesales adecuadas que
} 
El artículo 54 de la Ley de Protección del Consumidor se ha encargado de regular los efectos de la sentencia definitiva dictada en un proceso de este tipo, disponiendo que "la sentencia ejecutoriada que declare la responsabilidad del o los demandados producirá efectos erga omnes...", lo que implica que nuestro legislador ha optado por extender los efectos de la sentencia a todo el grupo de consumidores afectados, hayan o no intervenido en el proceso ${ }^{41}$.

\title{
1. Análisis de algunos aspectos relevantes de la normativa chilena
}

\author{
a) En cuanto a la determinación \\ del ámbito subjetivo de la sentencia
}

En primer término, debe estarse a lo dispuesto por el artículo $53 \mathrm{C}$ de la ley, acerca del ámbito subjetivo de la sentencia y, en concreto, acerca de los

permitan poner en práctica instituciones sustantivas, como la declaración de nulidad de cláusulas abusivas, y el ejercicio de acciones colectivas resueltas por medio de una sentencia única. De esta manera, se evita recargar a las partes y a los tribunales de manera innecesaria con centenares y, a veces, miles de casos iguales. La defensa de los intereses generales de los consumidores es una institución que ya forma parte de la legislación comparada y tiene efectos económicos importantes en la demanda (consumidores) y en la oferta (proveedores). En efecto, por el lado de los consumidores, permitirá dar solución a problemas de consumo masivos en los que, por distintas razones, actualmente no se otorga la debida protección (costo de reclamar mayor al beneficio del reclamo, dificultades en dicho proceso, dificultad para tomar conocimiento de la ocurrencia de una infracción, entre otras). Por el lado de la oferta, un mecanismo como el que se propone, en que las soluciones son colectivas, desincentiva posibles prácticas de infracción masiva, en las cuales es un hecho cierto que sólo algunos consumidores reclaman y, por lo tanto, aun con multas y posibles indemnizaciones individuales, la conducta infraccional puede ser rentable. Desde el punto de vista procesal, la defensa de los intereses colectivos y difusos recoge el principio que sea el mismo tribunal habilitado para conocer las causas individuales el que resuelva las colectivas y difusas. Este procedimiento se articula en base a dos fases. La primera fase, de carácter declarativa, persigue la determinación de la responsabilidad del infractor. La segunda fase apunta, en su caso, a la determinación de las responsabilidades civiles, de manera de fijar las indemnizaciones que puedan reclamarse a partir de la declaración de responsabilidad infraccional. Este procedimiento contiene una serie de resguardos, como definir de manera taxativa los legitimados activos; establecer medidas de publicidad; regular el efecto de la sentencia innovando respecto de los principios tradicionales en materia procesal; e incorporar un mandatario común que tramite las eventuales demandas de indemnización de perjuicios".

${ }^{41}$ En la tramitación del proyecto de ley en la Cámara de Diputados esta disposición fue muy debatida. Se aseveró que "en la práctica en este aspecto, el proyecto vulnera lo que es una base institucional de una forma de relacionarse entre los chilenos de muy antigua data y que ha funcionado bien. Confiere características de ley a una sentencia, contraviene lo dispuesto por el Código Civil y confunde decisión judicial con ley. Nos asimila, a lo menos en esta parte, a una especie de regla de tradición anglosajona. Lo peor es injertar en un cuerpo jurídico que tiene una determinada tradición con instituciones de otro procedencia y cultura, porque nadie va a entender nada" (Intervención del Diputado Cardemil en la discusión general en la Cámara de 13 de mayo de 2003. Sesión 76). Esta posición en definitiva, no prosperó. Nos parece que la principal motivación para que una sentencia pueda producir efectos erga omnes es la de evitar la repetición constante de juicios posteriores al proceso colectivo, y cuya fundamentación última la constituye la economía procesal. En http://recursoslegales.bcn.cl.ns1.bcn. cl:2048/jspui-rl/bitstream/10221.3/619/1/HL19496.pdf [visitado el 25/01/2010]. 
pronunciamientos que en ella debe efectuar el tribunal. Así, además de dar respuesta a la pretensión colectiva formulada por la parte actora, en los términos en que se haya ejercitado, la ley exige al tribunal una serie de pronunciamientos adicionales:

i) Declarar la forma cómo los hechos han afectado el interés colectivo o difuso de consumidores y usuarios.

ii) Declarar la responsabilidad infraccional de los proveedores demandados en los hechos denunciados y la aplicación de las sanciones o multas que procedan.

iii) Es posible que la acción colectiva ejercitada tenga naturaleza condenatoria, ya sea de carácter dinerario, o bien de hacer, no hacer o dar cosas específicas o genéricas. En tal caso, la sentencia deberá declarar también la procedencia de las correspondientes indemnizaciones y el monto de dichas indemnizaciones, o disponer la devolución de lo pagado en exceso o la restitución del valor pagado, tratándose de productos defectuosos.

iv) Según el grado de determinación de los beneficiarios de la sentencia, la ley ha previsto dos reglas:

- Si es posible la determinación individual de todos los afectados el tribunal podrá ordenar que algunas de las reparaciones o devoluciones que procedan respecto de un grupo o subgrupo sean efectuadas por el demandando sin necesidad de esperar la comparecencia de los miembros del grupo o subgrupo, cuando determine que el juez cuenta con la información necesaria para individualizarlos y proceder a dichas reparaciones ${ }^{42}$.

- Si la determinación individual no es posible, la sentencia ordenará la publicación de avisos que permitan su conocimiento a todos los perjudicados por los mismos hechos, con el objeto de que comparezcan en el proceso y reclamen el cobro de las indemnizaciones o reparaciones que procedan ${ }^{43}$.

\section{b) En cuanto a la determinación de la cuantificación del daño}

Además de la posibilidad de que la sentencia se pronuncie a título directo sobre los derechos de terceros no litigantes, también se pueden plantear especialidades en cuanto a su contenido en relación con la determinación del importe de la condena, en caso de que la acción colectiva ejercitada se dirija a la obtención de una condena dineraria. En relación con la exigencia de cuantificación como requisito de admisibilidad de la demanda, hay que acudir a lo que dispone el

${ }^{42}$ Artículo 53 C, inciso final, LPC.

${ }^{43}$ Artículo 53 C, letra e), en concordancia con el artículo 54 inciso segundo, ambos de la LPC. 
artículo 254 del Código de Procedimiento Civil, donde se establece que se fijará con claridad y precisión lo que se pida. El problema está en determinar si se cumple con esta exigencia si la petición no se ha cuantificado.

Debe, por tanto, recurrirse al artículo 51 de la LPC, que dispone como regla general en su numeral $2^{\circ}$, que "sin perjuicio de los requisitos generales de la demanda, en lo que respecta a las peticiones relativas a perjuicios, bastará señalar el daño sufrido y solicitar la indemnización que el juez determine, conforme al mérito del proceso, la que deberá ser la misma para todos los consumidores que se encuentren en igual situación". Por otra parte, el tribunal, en su sentencia, o bien fijará el importe exacto de la condena, o bien las bases para su liquidación, en los mismos términos. Ahora bien, si no resulta posible ni la cuantificación exacta ni la fijación de bases precisas, la sentencia tendrá un valor meramente declarativo de la obligación de pago, pero será preciso el desarrollo de un proceso declarativo posterior, cuyo objeto será precisamente la cuantificación del importe debido.

Para algunos autores resultaría inadmisible desde el punto de vista de los principios tradicionales del proceso, una cuantificación que presentara un cierto grado de indeterminación, pero reconocen que desde un punto de vista práctico, resultaría positivo el hecho que la demanda y la sentencia presenten una cierta indeterminación respecto del monto de las indemnizaciones, concretándose éstas definitivamente durante la etapa de ejecución de la sentencia ${ }^{44}$.

En principio, si se trata de la tutela de intereses colectivos, en los que están determinados los eventuales consumidores afectados por el hecho dañoso y beneficiarios de la condena dineraria, cabe pensar en una posible aplicación de esta regla general. Ahora bien, siendo difusos los intereses, es prácticamente imposible que se pueda cuantificar el importe de la condena, ni siquiera de forma relativa, a través de bases meramente matemáticas, desprovistas de valoraciones fácticas, lo que acarrearía la imposibilidad práctica de ejecutar la sentencia. Pero éste constituye un resultado incompatible con los criterios de eficacia en la protección a los consumidores que inspiran la regulación de la LPC. Por eso, es razonable entender que basta con que la sentencia establezca una determinación de los datos, características y requisitos necesarios para poder exigir el pago. En consecuencia, si el importe de la condena no está liquidado en la sentencia, será al proceder a su ejecución cuando se deba proceder a su cuantificación ${ }^{45}$.

\footnotetext{
${ }^{44}$ Cfr. Garnica, "Artículo 221", cit. nota n. 17, p. 864.

${ }^{45}$ Así ha sido previsto por el legislador chileno cuando en el artículo 54 B, dispone que los interesados podrán comparecer en el juicio una vez publicados los avisos dando cuenta de la sentencia, para que puedan ejercer los derechos que en ella se establecen.
} 


\section{c) En lo que respecta al ámbito y eficacia de la cosa juzgada}

\section{i) Regla General}

El legislador chileno ha optado en este punto por una decisión clara, recogida en el art. 54 LPC, cuando dispone que "la sentencia ejecutoriada que declare la responsabilidad del o los demandados producirá efectos erga omnes, con excepción de aquellos procesos que no hayan podido acumularse conforme al número 2) del inciso final del artículo 53, y de los casos en que se efectúe la reserva de derechos que admite el mismo artículo" ${ }^{46}$.

Por lo tanto, la sentencia dictada producirá efectos de cosa juzgada no sólo respecto de los litigantes concretos sino, sobre todo, respecto de todos los consumidores que se hayan visto afectados por el hecho dañoso que ha motivado el ejercicio de la acción y la posterior sentencia firme. Lo anterior se funda en el hecho que el legislador ha querido que exista solamente un proceso colectivo $y$, a lo sumo, varios procesos individuales, ya sea separados o acumulados al procedimiento colectivo.

ii) Supuesto en que se rechace la pretensión contenida en la demanda

El artículo 54 inciso final ha contemplado la hipótesis de que se niegue lugar a la demanda colectiva y la posibilidad excepcional de iniciar un nuevo procedimiento también colectivo. En ese caso, ha dispuesto que "cualquier legitimado activo podrá interponer, dentro del plazo de prescripción de la acción, ante el mismo tribunal y valiéndose de nuevas circunstancias una nueva acción, entendiéndose suspendida la prescripción a su favor por todo el plazo que duró el juicio colectivo. El tribunal declarará encontrarse frente a estas nuevas circunstancias junto con la declaración de admisibilidad de la acción dispuesta en el artículo 52".

Esta solución, distinta a la ya mencionada doctrina de la no obligatoriedad de los efectos de la sentencia desfavorable (o extensión secundum eventum litis), parece encontrar su antecedente inmediato en el Derecho brasileño, legislación que ha contemplado la posibilidad de iniciar un nuevo proceso colectivo si la sentencia que niega lugar a la demanda se funda en la insuficiencia de pruebas derivada de la mala instrucción del proceso, pudiendo cualquier legitimado proponer la misma acción presentando en el nuevo juicio nuevo material probatorio, debiendo convencer al magistrado de que la prueba es efectivamente nueva ${ }^{47}$.

\footnotetext{
${ }^{46}$ Que se encuentran contempladas en los artículos 53 y 54 C y que se refieren a la posibilidad que tienen los consumidores de intervenir en el procedimiento efectuando una reserva de sus acciones en la etapa de admisibilidad de la acción colectiva o en la etapa de ejecución de la sentencia. Además, se contempla una excepción respecto de los procesos que no hayan podido acumularse al procedimiento colectivo.

${ }^{47}$ Cfr. GiDı, "Cosa juzgada", cit. nota n. 10, pp. 280 y ss. Señala el autor que "Si la 'nueva prueba' se limita a reafirmar lo que ya se sabe y no añada nada a la convicción del magistrado, no debe ser
} 
Si el representante no pudo encontrar o no presentó todas las pruebas significa que representó inadecuadamente los intereses del grupo ante el tribunal. Por una parte, la vigilancia judicial de la representación adecuada en las acciones colectivas brasileñas es más fuerte que en el sistema de los Estados Unidos, ya que la inadecuación de la representación en la acción colectiva previa se presume si nuevas pruebas son presentadas en la segunda acción colectiva. Por otra parte, si la acción colectiva no es bien fundamentada jurídicamente o si el abogado preparó el caso en forma incompetente, la sentencia desfavorable sí producirá cosa juzgada ${ }^{48}$.

Siguiendo este criterio, la legislación chilena prevé la posibilidad de iniciar un nuevo proceso colectivo, siempre que el legitimado activo que proponga la acción se valga de "nuevas circunstancias". El problema que plantea la redacción de este artículo es la determinación del alcance de la expresión "nuevas circunstancias". No resuelve el legislador si la expresión se refiere a nuevas circunstancias de hecho o a nuevas pruebas que no se hayan rendido anteriormente ni tampoco a cómo se califica el hecho de encontrarnos efectivamente ante la existencia de circunstancias de esta naturaleza ${ }^{49}$.

\section{d) En lo que respecta a la publicidad de la sentencia}

Un correcto sistema de publicidad es esencial en un procedimiento en que se ha contemplado la eficacia erga omnes de la sentencia que se pronuncia. De él, además, derivan beneficios concretos para los consumidores.

Dispone el artículo 54 de la LPC, que para efectos del pago de las indemnizaciones o reparaciones, la sentencia condenatoria será notificada mediante avisos publicados a lo menos en dos oportunidades distintas, en los diarios que

considerada como 'nueva prueba'. El criterio que debe implementar el aplicador del derecho debe ser sustancial y no meramente formal. La nueva prueba debe ser sustancialmente innovadora y no apenas formalmente nueva".

${ }^{48}$ En todo caso, la legislación brasileña, como requisito de seriedad de la segunda demanda colectiva, exige que la nueva prueba sea acompañada conjuntamente con la presentación de la nueva demanda. Cfr. en este punto, GIDI, Antonio, Las acciones colectivas y la tutela de los derechos difusos, colectivos e individuales en Brasil, Universidad Nacional Autónoma de México, México, 2004, pp. 100 y ss.

${ }^{49} \mathrm{Si}$ nos atenemos a la historia fidedigna de la redacción de la Ley $\mathrm{N}^{\circ} 19.955$, el vocablo circunstancia es un argumento para afirmar que la novedad puede referirse no sólo a hechos nuevos, recién ocurridos o recién descubiertos, sino también a nuevos medios de comprobación aunque estén vinculados con hechos que no son nuevos ni desconocidos, inclusive que antes pudieran haberse alegado. Sobre este particular, es preciso considerar que en el proyecto original se instituía como excepción al efecto extensivo de la sentencia, que se hubiere rechazado la demanda por insuficiencia de pruebas, caso en el que podía renovarse la acción. El texto actual tiene su origen en el que se propuso en el segundo informe de la Comisión de Economía del Senado y, parece apoyado en el propósito de incentivar las posibilidades de renovar la acción por lo que la causal de insuficiencia probatoria estaría incluida. En http://recursoslegales.bcn.cl.ns1.bcn.cl:2048/jspui-rl/bitstream/10221.3/619/1/HL19496.pdf [visitado el 25/01/2010]. 
el juez determine, con un intervalo no inferior a tres ni superior a cinco días entre las publicaciones. En el caso que el número de afectados sea pequeño, el juez podrá disponer otra forma de notificación, que permita asegurar el conocimiento de todos ellos. Las menciones que debe contener el aviso se encuentran señaladas en el artículo $54 \mathrm{~A}$ de la ley ${ }^{50}$.

\section{La acción ejecutiva en el proceso de consumidores y usuarios}

Ante la necesidad de permitir condenas abiertas en cuyos procesos de ejecución pudieran comparecer los afectados que acreditaran su calidad de miembros del grupo y que pudieran beneficiarse de la extensión subjetiva de los efectos de la sentencia, la tendencia normativa era la de incluir una norma que regulara específicamente la ejecución de la sentencia dictada en procesos de consumidores y usuarios.

Dispone el artículo 54 C que una vez publicado los avisos que dan cuenta de la sentencia, los interesados deben presentarse a ejercer sus derechos dentro de los noventa días contados desde el último aviso, y podrán comparecer personalmente o patrocinados por un abogado, pero si se ha designado un procurador común, deberán actuar a través de éste y de acuerdo con las reglas generales ${ }^{51}$.

La presentación que haga el interesado se limitará a acreditar su condición de miembro del grupo afectado ${ }^{52}$. El objetivo de este artículo es evitar que los consumidores y usuarios que no hayan comparecido en el proceso tengan que iniciar un nuevo proceso declarativo para obtener individualmente una sentencia favorable, y por lo tanto, "el consumidor que no ha intervenido en el proceso y que entienda reunir los caracteres o requisitos establecidos en la sentencia de condena para extender a su propia situación jurídica los efectos de la misma, puede obtener el reconocimiento de su derecho de una manera sencilla, rápida y directa, sin necesidad de acudir a un nuevo procedimiento de declaración contra el deudor declarado en la sentencia, el que ha puesto en el mercado los bienes o servicios que han ocasionado el perjuicio" ${ }^{\prime 53}$.

\footnotetext{
${ }^{50}$ Entre las que destacan la identificación del grupo y la forma y el plazo en que los interesados deben hacer efectivos sus derechos, y las instituciones a las que los interesados podrán concurrir en busca de orientación e información.

${ }^{51}$ Entendemos que las reglas generales son las contenidas en los artículos 18 y siguientes del Código de Procedimiento Civil.

${ }^{52}$ Así lo dispone el artículo 54 D de la ley.

${ }^{53}$ Moreno Catena, Víctor, "Artículo 519. Acción ejecutiva de consumidores y usuarios fundada en sentencia de condena sin determinación individual de los beneficiados", en El proceso civil, Doctrina, jurisprudencia y formularios, Ed. Tirant lo Blanch, Valencia, 2001, p. 4371. Esta solución ya había sido introducida en la legislación española por los artículos 110 y 111 de la Ley de Jurisdicción ContenciosaAdministrativa. El artículo 110 se refiere a la posibilidad de que los efectos de una sentencia dictada
} 
Sin perjuicio de lo anterior, el legislador ha previsto una nueva oportunidad para que los interesados puedan hacer reserva de sus derechos, para perseguir la responsabilidad civil derivada de la infracción en un procedimiento distinto, que tendrá por objeto exclusivo la determinación del monto de las indemnizaciones que procedan, ya que se prohíbe discutir la existencia de la infracción ya declarada en el procedimiento colectivo. Salvas estas excepciones, el legislador, en el inciso tercero del artículo 54 C, prohíbe el ejercicio de nuevas acciones fundadas en los mismos hechos ${ }^{54}$.

Vencido el plazo de 90 días al que hace referencia el artículo 54 C, se dará traslado de todas las presentaciones al demandado, para que controvierta la calidad de miembro del grupo de uno o más de los interesados en el plazo de 10 días, plazo que puede ampliarse por resolución fundada y a petición de parte.

Podrá abrirse un término especial de prueba si el juez estima que existen hechos sustanciales, pertinentes y controvertidos, el que se regirá por las reglas de los incidentes. Contra la reposición que falla el incidente procederá la reposición y la apelación en subsidio de la reposición, y una vez fallado este incidente, queda fijado de modo permanente el monto global de las indemnizaciones o reparaciones que deberán pagarse por el demandado.

En cuanto al tribunal que debe conocer del incidente, como el artículo nada dice, hay que estar a la regla contenida en el 231 del Código de Procedimiento Civil, de lo que cabe deducir que el juez competente es el que haya conocido de la demanda colectiva en primera instancia, que además será competente para conocer de la correspondiente ejecución.

En relación con el pago de las indemnizaciones, el demandado debe efectuar las reparaciones o consignar el monto íntegro de las indemnizaciones dentro del plazo de 30 días corridos, contados desde aquel en que se haya fallado el incidente promovido en relación con la acreditación de la calidad de interesados.

en materia tributaria y de personal de servicio de la Administración Pública, y que ha reconocido los efectos de una situación jurídica individualizada en favor de una o varias personas, puedan extenderse a otras si concurren las circunstancias descritas en ese precepto, y el artículo 111 prevé la posibilidad de que el Tribunal que conoce de la ejecución de la sentencia extienda a los afectados por la suspensión de la ejecución del fallo por un recurso de apelación pendiente, los efectos de las sentencias firmes que hayan recaído en recursos ya resueltos. Cfr. también Rosende VILLAR, Cecilia, La eficacia frente a terceros de las sentencias contencioso-administrativas, Ed. Aranzadi, Navarra, 2002, pp. 159 y ss.

${ }^{54}$ Una vez que se ha dictado sentencia firme en un proceso entablado por una entidad provista de legitimación colectiva, la voluntad legal es clara: no pueden iniciarse más procesos y, en especial, que no puedan los consumidores, a título individual, pretender tutelas individualizadas o distintas de lo que se desprenda de la sentencia colectiva. Esta limitación en cuanto al posible ejercicio de acciones con posterioridad por consumidores aislados resulta especialmente asumible si se tiene en cuenta la existencia de un Ilamamiento colectivo al proceso de los sujetos que se verán después afectados por la extensión ultra partes de la cosa juzgada de la sentencia. 
Si a juicio del tribunal el pago de estos montos globales produce en el demandado un detrimento patrimonial significativo de modo que pudiera estimarse que quedará próximo a la insolvencia, el juez podrá establecer un programa mensual de pago de indemnizaciones completas para cada demandante o bien determinar una forma de cumplimiento alternativo del pago, pudiendo exigir alguna forma de fianza u otra caución si la situación económica del demandado así lo permite ${ }^{55}$.

Si la sentencia no es cumplida por el demandado, la ejecución se efectuará a través del procurador común en un único procedimiento, por el monto global de las indemnizaciones o reparaciones o por el saldo total insoluto, efectuándose el pago a los interesados a prorrata de sus derechos declarados en la sentencia definitiva.

\section{BibLIOGRAFíA}

Acosta Estévez, José, Tutela procesal de los consumidores, Bosch, Barcelona, 1995.

Aguirrezabal Grünstein, Maite, "Algunas precisiones en torno a los intereses supraindividuales (colectivos y difusos)", Revista Chilena de Derecho volumen XXXIII, No 1, 2006.

, "El procedimiento para la defensa de intereses colectivos y difusos de consumidores y usuarios en la ley de protección del consumidor", en La protección de los derechos de los consumidores en Chile, Cuaderno de Extensión Jurídica, Facultad de Derecho, Universidad de los Andes, Santiago, 2006.

Almagro Nosete, José, "La protección procesal de los intereses difusos en España", Justicia No 1, 1983.

Bachmaier Winter, Lorena, "Cuestiones procesales relativas a la defensa de los intereses colectivos de los consumidores y usuarios por el grupo de afectados", en Derecho de consumo, Acceso a la justicia, responsabilidad y garantía, Ministerio de Sanidad y Consumo, Consejo General del Poder Judicial, Madrid, 2001.

Barbosa Moreira, José, "A açao popular do direito brasileiro", en Studi in onore di Enrico Tullio Liebman, volumen IV, Ed. Guiffrè, Milano, 1979.

Bellido Penadés, Rafael, La tutela frente a la competencia desleal en el proceso civil, Ed. Comares, Granada, 1998.

, "La tutela de los intereses de los consumidores en la nueva Ley de Enjuiciamiento Civil", Tribunales de Justicia 1139-2002.

${ }^{55}$ Las sentencias que se dicten en relación con la forma en que debe procederse al pago no son susceptibles de recurso alguno. 
Bonet Navarro, Ángel, "Protección eficaz y acceso a la justicia de los consumidores", Estudios sobre Consumo 16, 1989.

Bordalí Salamanca, Andrés, "Efectos de la sentencia pronunciada en los procesos de tutela de intereses o derechos difusos", en Procesos colectivos. La tutela de los derechos difusos, colectivos e individuales en una perspectiva comparada, Ed. Porrúa, México, 2003.

Cappelletti, Mauro, "Appunti sulla tutela giurisdizionale di interessi collettivi o diffusi", en Le azioni a tutela di interessi colletivi. Atti del convegno di studio (Pavia, 11-12 giugno 1974), Cedam, Padova, 1976.

"Formaciones sociales e intereses de grupo frente a la justicia civil", Traducción de Brañes, Raúl, Boletín Mexicano de Derecho Comparado 31 32 Año XI, enero-agosto, 1978.

CARPI, Federico, L'efficaccia ultra partes della sentenza civile, Ed. Giuffrè, Milano, 1974.

Cordón Moreno, Faustino, "El acceso a la justicia civil de los derechos de los consumidores", Estudios sobre consumo 16, 1989.

Cortés Domínguez, Valentín, Derecho procesal civil. Parte general, $3^{a}$ Edición, Ed. Colex, Madrid, 2000.

Couture, Eduardo, Fundamentos de Derecho Procesal Civil, Ed. Depalma, Buenos Aires, 1989.

Chiovenda, Giuseppe, Principios de derecho procesal Civil, vol. II, 5ª Edición, Ed. Temis, Buenos Aires, 1965.

Damián Moreno, Juan, "Artículo 221", Comentarios a la nueva Ley de Enjuiciamiento Civil, Lex Nova, Valencia, 2000.

De la Oliva Santos, Andrés, "Sobre la protección jurisdiccional de los consumidores y usuarios", Estudios sobre consumo 16, 1989.

, Sobre la cosa juzgada (civil, contencioso-administrativa y penal, con examen de la jurisprudencia del Tribunal Constitucional), Centro de Estudios Ramón Areces, Madrid, 1991.

DentI, Vittorio, "Le azioni a tutela di interessi collettivi", en Le azioni a tutela di interessi collettivi, Ed. Cedam, Padova, 1976.

Garnica Martín, Juan, "Artículo 221. Sentencias dictadas en procesos promovidos por asociaciones de consumidores y usuarios", en Comentarios a la nueva Ley de Enjuiciamiento Civil, Ed. Iurgium, Barcelona, 2000.

GIDI, Antonio, Las acciones colectivas y la tutela de los derechos difusos, colectivos e individuales en Brasil, Universidad Nacional Autónoma de México, México, 2004.

Gómez de Liaño GonZÁlez, Fernando, "La legitimación colectiva y el artículo $7^{\circ}$ de la Ley Orgánica del Poder Judicial", Justicia 3, 1986. 
GutiérRez de CABIedes, Pablo, La tutela jurisdiccional de los intereses supraindividuales: colectivos y difusos, Aranzadi, Navarra.

"La nueva Ley de Enjuiciamiento Civil y los daños con múltiples afectados", en Derecho del consumo. Acceso a la justicia, responsabilidad y garantía, Ministerio de Sanidad y Consumo, Consejo General del Poder Judicial, Madrid, 2001.

LieBMAn, Enrico Tulio, Eficacia y autoridad de la sentencia, (Traducción de Santiago Sentís Melendo), Ediar, Buenos Aires, 1939.

Montero Aroca, Juan, La prueba en el proceso civil, $4^{\text {a }}$ Edición, Ed. ThomsonCivitas, Navarra, 2005.

Moreno Catena, Víctor, "Artículo 519. Acción ejecutiva de consumidores y usuarios fundada en sentencia de condena sin determinación individual de los beneficiados", en El proceso civil, Doctrina, jurisprudencia y formularios, Ed. Tirant lo Blanch, Valencia, 2001.

Pellegrini Grinover, Ada, "Eficacia y autoridad de la sentencia: el Código Modelo para Iberoamérica y la teoría de Liebman", en La tutela de los derechos difusos, colectivos e individuales homogéneos. Hacia un Código Modelo para Iberoamérica, Ed. Porrúa, México, 2003.

Proto PISANI, Andrea, "Appunti preliminari per uno studio sulla tutela giurisdizionale degli interessi collettivi (o piu esattamente supraindividuali) innanzi al giudice civile ordinario", en Le azioni a tutela di interessi collettivi, Ed. Cedam, Padova, 1976.

Punzı, Carlo, "La tutela giudiziale degli interesi diffusi e degli interessi colletivi", Rivista di Diritto Processuale 3, 1948.

Rodríguez López, R., "Tutela jurisdiccional de los derechos de los consumidores y usuarios", Actualidad Civil núm. 3, 1993.

Rosende VILLAR, Cecilia, La eficacia frente a terceros de las sentencias contenciosoadministrativas, Ed. Aranzadi, Navarra, 2002.

Silguero Estagnan, Joaquín, "Las acciones colectivas de grupo en España", en Procesos Colectivos, La tutela de los derechos difusos, colectivos e individuales homogéneos en una perspectiva comparada, Ed. Porrúa, México, 2004.

TAPIA FernÁndez, Isabel, "Artículo 221. Sentencias dictadas en procesos promovidos por asociaciones de consumidores y usuarios", en Comentarios a la Ley de Enjuiciamiento Civil, Ed. Aranzadi, Navarra, 2000.

VASAK KAREL, "Human rights: as a legal reality", The international dimensions of human rights, Greenwood Press, Connecticut, 1982.

VIGORITI, Vincenzo, Interessi Collettivi e proceso, La legitimazione ad gire, Ed. Giuffrè, Milano, 1979.

Vodanovic, Antonio, Curso de Derecho Civil, Parte General y Sujetos del Derecho, 4ª edición, Editorial Nascimento, Santiago de Chile, 1971. 
